\title{
LA DIALÉCTICA DEL FUNDAMENTO
}

\author{
CARLOS ARTURO LONDOÑO RAMOS* \\ Universidad Pedagógica y Tecnológica de Colombia.
}

\section{Resumen}

En la Fenomenología del Espíritu, la dialéctica de Hegel planteó un diálogo entre el saber (la conciencia) y la autorreflexión (la autoconciencia) de tal manera que la fundamentación del saber se regía por los criterios establecidos por la filosofía (la razón). Otra forma de la fundamentación del saber se efectúa a través de la complejidad y dinamismo de los principios categoriales expuestos en la Ciencia de la Lógica. Después de Hegel, el marxismo y las filosofías epistemológicas han mostrado que la filosofía depende del proceso mismo del desarrollo de las ciencias y de las disciplinas. Así la filosofía dialéctica se torna dialógica en cuanto propone un diálogo entre el saber y el autosaber de la filosofía, o dicho de otra manera, la filosofía se transforma en un diálogo de interfundamentación y comunicación como respuesta coherente a la "crisis de los fundamentos" planteada por filosofías contemporáneas.

Palabras clave: fundamentación, dialéctica, Hegel.

\begin{abstract}
The dialectics of foundation.

In the Phenomenology of the spirit, Hegel's dialectic established a dialogue between knowledge (consciousness), and self-reflection (self consciousness) in such a way that the basis of knowledge was ruled by the criteria established by philosophy (reason). Another form of the foundation of knowledge is through the complexity and dynamism of the categorical principles presented in the Science of Logic. After Hegel, Marxism and epistemological philosophies have proved that philosophy depends on the process of the sciences and the development of disciplines. Thus, dialectic philosophy turns dialogical when it proposes a dialogue between knowledge and the self-knowledge of philosophy, or in other words, philosophy transforms into a dialogue of interfoundation and communication as a coherent response to the "crisis of foundations" determined by contemporary philosophies.
\end{abstract}

Key Words: Foundation, dialectics, Hegel.

\section{INTRODUCCIÓN}

\footnotetext{
* Selección de la Tesis Doctoral "Dialéctica Constructiva de las Ciencias", Universidad Javeriana, 1992. E-mail: londonocarlosarturo@ Hotmail.com
} 
La filosofía a lo largo de su historia ha buscado los fundamentos últimos del saber -lo que propiamente se ha denominado metafísica- es decir, es la exploración de los principios o criterios que nos sirven para juzgar racionalmente los saberes que consideramos como aceptables, tanto en el saber cotidiano, en las ciencias formales lógico-matemáticas, naturales y socioculturales, como en las disciplinas normativas y valorativas del derecho, la política y la crítica estética. Este movimiento de la fundamentación de los saberes en general, es una de las características centrales de la civilización que proviene de Grecia antigua y desemboca en la modernidad. En la Ilustración moderna, no se acepta ningún saber sustentado en la simple tradición, en la costumbre, ni en la autoridad. Todo es sometido a la crítica de la razón, al principio de razón suficiente, incluidos los límites de la razón misma.

A lo largo del siglo XX este proceso de fundamentación se ha tornado problemático, de una parte, por el crecimiento de las ciencias que han destronado principios considerados durante siglos como completamente firmes, y de otra, por la mayor conciencia de la historicidad del saber y de la relatividad cultural y lingüística.

El desarrollo científico ha mostrado la posibilidad de diversas verdades formales como en las geometrías no euclidianas y múltiples formalizaciones de la lógica; la física relativizó el modelo teórico newtoniano (el espacio y el tiempo absolutos); planteó la equivalencia de la masa y la energía; propuso una forma de localización física como la onda-partícula en la que los cuerpos aparecen como "distribuidos" en vez de estar en un sitio fijo; al lado de las leyes deterministas surgen las leyes estadísticas y la incertidumbre; la química clásica se amplió a la foto-química; la biológica ha mostrado el parentesco e interdependencia ecológica de todas las formas de vida y se formalizó en con el ADN. Las ciencias socioculturales por su parte, se han abierto al pluralismo, es decir, a la conciencia de que no es posible agotar todas las dimensiones de la organización social e individual con un sólo método y desde una sola perspectiva.

La filosofía misma ha cuestionado la universalidad de los conocimientos, las posibilidades de la totalidad del saber pretendida por los grandes sistemas filosóficos, así como también, ha mostrado la dependencia de los saberes de las condiciones sociales, los intereses y de las comunidades científicas. Los principios y criterios del conocimiento establecidos en la experiencia y el entendimiento, también se han relativizados porque la experiencia depende de nuestras interpretaciones y los criterios del entendimiento se han tornado históricos. Así mismo, el giro linguiístico, que ha dado la filosofía según el cual el saber depende del significado socialmente compartido, ha puesto en cuestión la filosofía moderna que puso su base en la certeza en la subjetividad y en la razón individual que sólo dialoga consigo misma a través de su propia autoevidencia. Todo este recorrido ha generado en la segunda mitad del siglo $\mathrm{XX}$, un "pensamiento débil"1 y un escepticismo según el cual no es posible

1. La propuesta filosófica del "El Pensamiento débil", o de la "Hermenéutica ontológica", denominada también "posestructuralista", designa un movimiento de desfundamentación que defiende un pensar no sometido al principio de razón suficiente. Gianni Vattimo inspirado en las últimas obras de Heidegger y en Nietzsche, muestra como la tradición metafísica (como 
establecer criterios éticos universales, ni son posibles la verdad, la universalidad y ni la totalidad y, en últimas, ni siquiera sería posible la razón. Todo saber puede disolverse en conversaciones o en metáforas.

A pesar de todos estos cuestionamientos a la tradición filosófica de la fundamentación, es posible sustentar una tesis filosófica que sin caer en el escepticismo unilateral, también evite aferrarse al dogmatismo de las verdades eternas, es decir, se requiere una filosofía dialéctica falibilista que no renuncie a la verdad objetiva cuasi-relativa, ni a la universalidad presuntiva ni a la totalidad abierta. Una filosofía dialéctica falibilista, piensa bajo la conciencia histórica de la superación de los saberes a partir de la corrección de los errores, se sustenta de la argumentación racional y en la coordinación de perspectivas. La fundamentación filosófica, entonces es posible pero como un saber dinámico que se retroactiva con los mismos saberes, es decir como filosofía transcientífica y posmetafísica que ha renunciado a buscar un principio último y único, pero que no renuncia a un a fundamentación dialógica y pluralista del saber.

A través de la historia, la filosofía ha tenido una relación privilegiada con las ciencias y las disciplinas, en una palabra: con el saber. El proceso que conduce de la conciencia del saber a la autoconciencia, es decir, a la autorreflexión, está unido a la historia del saber efectivo. El proceso de la autorreflexión filosófica, a través de su devenir se ha efectuado en relación con el saber del objeto de las ciencias y de las disciplinas, por lo cual la filosofía, como autosaber, se ha ocupado de examinar tanto sus condiciones antropológicohistóricas (recursos socioeconómicos, intereses, poderes, contextos del lenguaje, prejuicios, etc.), como las condiciones de validez del saber, que, siguiendo a Habermas, ${ }^{2}$ se pueden tipologizar de acuerdo a las funciones del lenguaje en la verdad, la legitimidad normativa y la valoración, de una parte, y en las pretensiones de éxito de la acción instrumental, de otra. Las primeras, las condiciones sociohistóricas conforman recursos, limitaciones, posibilidades, modelos, obstáculos y presiones para el acceso a la validez del saber; las segundas examinan los "marcos" o condiciones del saber acaptable como válido.

horizontes del pensar) culmina en el pensamiento de la representación culculista, objetivador e instrumental de la ciencia y la técnica moderna que sólo se interesan por los entes en cuanto objetos y dejan a un lado ("olvidan") el horizonte de pensamiento (el ser) del que dependen: por la misma razón, imponen esta forma de pensar y actuar hasta que lo absolutizan. En contra de la metafísica racionalista, esta tesis concluye en la defensa de las ciencias humanas hermenéuticas que exploran las significaciones sin que puedan someterse a los criterios de la precisión y el cálculo, antes bien, exploran los horizontes del sentido histórico en el lenguaje y concluyen en un pensamiento "estetizante".

No obstante, consideramos que en toda la historia de la filosofía han convivido tanto el racionalismo riguroso como la hermenéutica débil, ésta no puede pretender sustituir el racionalismo con el pensamiento estético, pues éste, además, también se evalúa argumentativamente según su valor filosófico-literario. El movimiento de desfundamentación, representa, en consecuencia, una crítica a la unilateralidad del "racionalismo exagerado" y al reductivismo pragmático-positivista. Según Vattimo, la "ultrametafísica" heideggeriana no un rechazo al pensamiento científico-técnico, es, más bien, una especie de "complemento".

Cfr. VATTIMO, G. Las aventuras de la diferencia: pensar después de Nietzsche y Heidegger. Trad. Juan Carlos Gentile. Barcelona: Ediciones Península, 1980.

2 . HABERMAS, J. Teoría de la acción comunicativa: racionalidad de la acción y racionalización social. T. I. Trad. Manuel Jiménez Redondo. Madrid: Taurus, 1989. 


\section{LA DIALÓGICA DEL SABER.}

La dialéctica, en el sentido platónico, es la división y reunificación de los de las ideas genéricas por medio del diálogo. Hegel retoma la significación griega para referirse a la escisión y reintegración del saber en la conciencia que dialoga consigo misma. En la introducción a la Fenomenología del Espíritu, Hegel circunscribe la filosofía al método del examen del saber tal como éste se manifiesta, pues el saber aparece como fenómeno: se hace patente en su exposición, es decir, se expone en el conocimiento común, en las ciencias, en la ética y las instituciones políticas, tanto como en la "cultura espiritual" del arte, la religión y la filosofía.

La filosofía es un examen del saber en general y como todo examen implica unos criterios: la filosofía investiga precisamente estos criterios o pautas por las cuales habría de regirse el saber. La primera dificultad aparece cuando, desde el comienzo, no se pueden establecer tales criterios, puesto que la filosofía no debe prejuzgar el conocimiento ni aseverar arbitrariamente unas pautas para evaluar el saber. Antes de estipular los criterios del saber deben establecerse las determinaciones del saber, o sea, "la ontología de la conciencia", dice Hegel.

En el diálogo entre la conciencia y la autoconciencia el pensamiento establece nuevos órdenes de la verdad (en el sentido amplio de validez). Para Hegel, esta dialéctica se produce entre el saber del objeto (saber en sí), el saber para la conciencia (saber para sí) que denominamos "autosaber" y el saber fenomenológico (saber en sí y para sí) que es el proceso de transformación que se genera por el diálogo entre el saber y la autorreflexión (en términos de Hegel "saber para nosotros": la filosofía). Por medio de este proceso se produce el cambio del modo de pensar y ésta es la experiencia de la conciencia. Esta triple relación es, para Hegel, una identidad de opuestos en el interior de la conciencia.

Hegel considera que el camino (metodon) hacia la Ciencia filosófica consiste en:

Este movimiento dialéctico, que la conciencia lleva a cabo en sí misma, tanto en su saber como en su objeto, en cuanto brota ante ella el nuevo objeto verdadero es propiamente lo que se llamará experiencia [de la conciencia...]. Vemos que la conciencia tiene ahora dos objetos: uno es el primer en sí, otro el ser para ella de este en sí. El segundo sólo aparece por el momento, la reflexión de la conciencia en sí misma [...] el primer objeto cambia, deja de ser el en sí para convertirse en conciencia de un objeto que es en sí solamente para ella, lo que quiere decir, a su vez, que lo verdadero es el ser para ella de este en sí y, por lo tanto, que esto es la esencia o su objeto. El nuevo objeto contiene la anulación del primero, es la experiencia hecha sobre él" 3

3 . HEGEL, G. Fenomenología del espíritu. Trad. Wenceslao Roces. México: Fondo de Cultura Económica, 1966. pp. 58-59. 
En el devenir del saber se expresa el cambio de los criterios y de los objetos de conocimiento. Al cambiar los objetos de conocimiento, cambian igualmente los criterios; tal como se puede observar en la transformación de la política feudal de servidumbre a la igualdad republicana. Así se descubre como dice Hegel- que el objeto anterior, que se tenía por verdadero, cede su lugar a otro concepto del objeto. Así en el conocimiento se concluye que el saber pasado no era más que nuestro supuesto saber y no el objeto mismo. Este proceso cambia también la conciencia misma que el ser humano tiene de sí.

En palabras de Hegel:

Lo cual se presenta aquí de modo siguiente: cuando lo que primeramente aparecía como el objeto desciende en la conciencia a un saber de él y cuando el en sí deviene un ser del en sí para la conciencia, tenemos el nuevo objeto por medio del que surge también una nueva figura de la conciencia, para la cual la esencia es ahora algo distinto de lo que era antes. ${ }^{4}$

La cultura intelectual está en relación con la formación de la conciencia: como saber y como autosaber. El examen de la autoconciencia es un comparar y resulta ser la instancia decisiva dado que es la que establece los criterios:

En efecto -afirma Hegel-, la conciencia es, de una parte, conciencia del objeto y, de otra, conciencia de sí misma; conciencia de lo que es para ella lo verdadero y conciencia de su saber de ello. Y en cuanto que ambas son para ella misma, ella misma es su comparación; es para ella misma si su saber del objeto corresponde o no a éste 5 .

Para Hegel, si se investiga el saber en su interior, se encuentra una triple diferencia: el saber de los objetos, el saber del saber que simultáneamente es un saber de sí mismo, y el proceso de desarrollo de esta relación. ${ }^{6}$ La distinción entre saber y autosaber radica en la división entre conciencia de los objetos y la autoconciencia de este saber. La diferencia entre estos dos planos del saber se genera en el interior del pensamiento mismo. La autoconciencia es una acción del pensamiento sobre sí mismo en la forma del autoexaminarse: es el sujeto del sujeto. Si el saber siempre está acompañado de conciencia ésta, además, puede ser objeto de sí misma, y en el proceso de comparación, se transforma la conciencia tanto de modo metodológico en la filosofía (llevado a cabo por el individuo) como en el proceso histórico de toma de conciencia.

\footnotetext{
4 . Ibid. p. 59.

5 . Ibid. p. 58.

6. Jorge Aurelio Díaz expone la relación simultánea entre conciencia y autoconciencia: “...que el conocimiento del mundo no se vaya dando sino en la medida en que progresa el conocimiento de sí, y viceversa; produciéndose entre ambos momentos una mutua dependencia, pero no unívoca, ya que la autoconciencia es el punto de partida y la meta del conocer". Cfr. DIAZ, A. Jorge Aurelio. Estudios sobre Hegel. Bogotá: Universidad Nacional de Colombia, 1986, pp. 50-51
} 
Según Heidegger, en su interpretación de Hegel, el sentido fundamental de la dialéctica es el diálogo. La dialéctica (dialegestai) es un manifestarse entre, o a través (dia), del coloquio (legein), de tal modo que, como dialógica, la conciencia es una conversación y una reunión entre el saber óntico (de los entes) y el ontológico (del orden del ser). El diálogo es el aparecer o el fenómeno de la conciencia; en este proceso, la conciencia recorre el camino de su experiencia. La experiencia de la conciencia es su ser. ${ }^{7}$ En este análisis por el cual la experiencia de la conciencia es el diálogo, la reflexión de Heidegger coloca lo ontológico, en el lugar de la autoconciencia, y en el lugar de de la conciencia sitúa lo óntico o el saber los objetos. No obstante, en la filosofía de Heidegger se produce un cambio, se elimina la evolución de la autoconciencia efectuada a partir de su propia crítica y superación de los estadios anteriores, tal como es la tesis de Hegel, y se sustituye por el devenir del ser como destino, en el cual no participan los sujetos, simplemente el ser adviene, se impone en cada época.

La dialéctica planteada tanto por Hegel como en la versión heideggeriana es fundamentalmente un diálogo vertical entre el saber y los criterios de la filosofía en el que predomina la última. Aunque en la práctica de sus reflexiones Hegel tiene en cuenta el devenir de las ciencias que han tornado complejos y dinámicos los principios categoriales, ${ }^{8}$ considera a la filosofía como la instancia decisiva para juzgar las ciencias en general.

Heidegger, en La Pregunta por la cosa observa la existencia de la filosofía en el interior de las reflexiones científicas tal como sucede con la física contemporánea, y aún más, considera que el surgimiento de la ciencia moderna sólo pudo aparecer bajo el horizonte del nuevo pensamiento metafísico, en el sentido de que plantea como fundamentales los principios del conocimiento matemático de la naturaleza, así como de crítica conceptual y los nuevos métodos. Así para Heidegger, la ciencia moderna:

...exigió también una amplitud y seguridad extraordinaria del pensamiento conceptual, y finalmente un dominio de las nuevas experiencias y métodos. Todo esto suponía un singular apasionamiento del anhelo por un saber normativo, que no tiene igual más que en los griegos, un saber, que ante todo y constantemente cuestiona sus propios supuestos, y trata de encontrarles un fundamento. ${ }^{9}$

A pesar de que Hegel piensa la dialéctica como un diálogo de la conciencia y la autoconciencia -y Heidegger, igualmente, entre lo ontológico y lo óntico-, en los dos casos, dialéctica es fundamentalmente un monólogo con lo cual los diferentes niveles del saber pierden capacidad de confrontación mutua. El saber es absorbido por la filosofía y, cono resultado, se limita la capacidad

7 . Cfr. HEIDEGGER, M. "El concepto hegeliano de experiencia". En: Sendas perdidas.

Buenos Aires: Losada, 1960. pp. 100-173.

8. Cfr. GARAUDY, R. Dios ha muerto: Estudio sobre Hegel. Trad. Alfredo Llanos, Buenos

Aires: Ediciones siglo XX, 1973. p. 155.

9 . HEIDEGGER, M. La pregunta por la cosa. Trad. Eduardo García B. y Zoltan Szankay.

Buenos Aires: Alfa Argentina, 1975, p. 62. 
crítica del saber del objeto (saberes cotidianos, las ciencias y disciplinas). La filosofía, en cuanto conciencia refleja, es el examen problematizador del saber en sus formas lógicas más generales y fundamentales. La filosofía, por ser un diálogo del saber social consigo mismo, en tanto referido a los objetos y a los sujetos, es un saber real (es La Ciencia, dice Hegel).

Con los grandes cambios que se han producido en las ciencias a lo largo del siglo XX, éstas se han vuelto parcialmente autónomas de la filosofía en general, pero han incluido la reflexión epistemológica en su propio interior, esto es lo que Piaget ${ }^{10}$ ha denominado epistemologías intracientíficas. De modo análogo Heidegger observa la existencia de la filosofía en el interior de las ciencias: "Allí donde hay una investigación auténtica y orientadora [...] Niels Bohr y Heisenberg, piensan de un modo completamente filosófico. Solamente por eso pueden crear nuevos planteos y sobre todo perseverar en la problematicidad."

Con la creciente autonomía de las ciencias y disciplinas, se va debilitando la tutela de la filosofía sobre el saber, al mismo tiempo que germinan las epistemologías regionales, intracientíficas o intradisciplinarias. Estos cambios no significan el fin de las epistemologías generales, pero sí su relatividad y la necesidad del diálogo con los saberes. En esta dirección, en una dialéctica dialogante, el saber también cuestiona los criterios y principios del autosaber. Los momentos del saber constituyen procesos recíprocos e históricos que conforman la conciencia social epistémica de cada época. Por esta razón, el diálogo del saber y del autosaber debe ser reinterpretado como una polémica y una cooperación intersubjetiva, interdisciplinaria y trasdisciplinaria (en el sentido de la relación entre saber y sociedad) y entre la filosofía y los saberes.

Esta triple alteridad significa la intrínseca referencia de unos a otros. La conciencia no podría existir sin sus contenidos y los contenidos constituyen la aprehensión ideal e histórico-social de los objetos del saber, de acuerdo con la evolución de las formas del pensar. Así, la filosofía como autosaber representa el auto-examen del saber desde sus fundamentos más radicales.

La alteridad es también recíproca: la autoconciencia se desarrolla con una mayor amplitud y profundidad, en la medida en que se delimitan sus contenidos y se forma la identidad del yo. El saber se objetiva y se universaliza en relación con el dominio de la naturaleza y la evolución de las estructuras sociales. La filosofía se auto-critica y se reorganiza, al volver sobre la historia y las crisis de las ciencias y disciplinas. En términos metafóricos, como dice Hegel, la razón sale de sí en la naturaleza para volver a sí misma.

Las ciencias y disciplinas establecen un diálogo con la filosofía. No es posible pensar que se puedan imponer unos fundamentos que no tienen sus raíces en la historia de las ciencias y de las disciplinas, de igual modo, tampoco es posible el desenvolvimiento de las ciencias sin unos criterios metodológico-racionales que anticipen su elaboración. El diálogo se efectúa entre el saber y el saber del saber. La filosofía es fundamentalmente una reflexión que dilucida el saber,

\footnotetext{
${ }^{10}$ Cfr. PIAGET, A. Naturaleza y métodos de la epistemología. Buenos Aires: Proteo, 1970.

${ }^{11}$. HEIDEGGER, M. La pregunta por la cosa. Op. Cit. p. 64 .
} 
es un saber duplicado y, en cuanto tal, es una toma de conciencia sobre las condiciones del saber tanto desde el punto de vista de las condiciones antropológico-históricas+ como de la aceptabilidad o validez del saber.

La experiencia histórica del saber contradice los conocimientos pasados. La producción de nuevos conocimientos se origina y es resultado de nuevos principios y criterios. Los criterios cambian, a su vez, si se modifican los asuntos del saber. El estudio de los objetos es, simultáneamente, un examen de las formas metodológico-racionales, tal como se manifiesta en el nacimiento del racionalismo y del empirismo, con el surgimiento de las ciencias naturales, a partir del siglo XVII; con las corrientes positivistas y dialécticas, en la formación de las ciencias socioculturales, en el siglo XIX.

Para Hegel, el término "ciencia" incluía todo saber sistemático y racionalmente sustentado -y que nosotros denominamos saber- y por esta razón, se contaba dentro de ella, no sólo a las ciencias naturales, sino también al derecho, la política y la filosofía. A lo largo del $\mathrm{XX}$, con el surgimiento de las epistemologías especializadas en las ciencias, se hizo necesario realizar una distinción en el interior del saber entre ciencias y disciplinas*. Según Piaget, ${ }^{12}$ las ciencias se ocupan de "leyes", o mejor, diríamos nosotros, de regularidades (incluidas las estructuras, tipologías, procesos y estadísticas), por el contrario, las disciplinas se ocupan, predominantemente, de normas y valores (derecho, crítica estética, política). Sin duda, esta diferencia es relevante, para aclarar diversas formas del saber, pero también la distinción es relativa dado que las ciencias socioculturales, en mayor o menor grado, combinan las explicaciones con la selección valorativa de hechos relevantes, tal es el caso de la historia o de la sociología jurídica. La filosofía como disciplina, propone criterios normativos y valorativos sobre la validez del saber, pero también expone el saber como fenómeno, es decir, como un saber social organizado racionalmente y condicionado de modo diverso.

El conocimiento filosófico sobre las ciencias y disciplinas puede mostrar sus "marcos generales", sus pretensiones injustificadas, y también marcar derroteros; a su vez, el saber del objeto destruye las evidencias, los principios y los criterios que la filosofía le ha impuesto. En las ciencias y disciplinas la "objetividad" consiste en la elaboración dialógica del objeto de conocimiento. Si bien, la objetividad es suprasubjetiva en cuanto aspira a la validez universal: es un conocimiento que está más allá de simple opinión del sujeto individual. Sin embargo, especialmente en las ciencias socioculturales, dada la diversidad de sus objetos y formas metodológicas, no se puede prescindir de cierto perspectivismo. Así, el saber también es comunicación intersubjetiva que se realiza como cooperación y lucha, como polémica múltiple.

El defecto de la exposición hegeliana está en no ser suficientemente consecuente consigo misma en la dialéctica del sujeto y el objeto, del saber y del autosaber y de los sujetos entre sí, pues, desde un punto de vista radical, no sólo es la conciencia la que se compara consigo misma; el objeto mismo,

${ }^{12}$. PIAGET, J. Psicología y epistemología. Trad. Francisco J. Fernandez Buey. Barcelona: Ariel, 1975, p. 153-189. 
natural o social, condiciona la conciencia y su propio despliegue, y la polémica intersubjetiva es la fuente de la toma de conciencia.

En la dialéctica del saber y del autosaber, también presupone una diferencia entre la conciencia de la opinión natural y la conciencia reflexiva. ${ }^{13} \mathrm{La}$ conciencia natural es directa, es decir, es consciente de su objeto y se da como referencia a lo otro: naturaleza y mundo sociocultural. En la conciencia directa, el pensar se refiere al objeto en conexión con el yo (puesto que es consciente), pero esta relación al propio autosaber es implícita, no es tematizada ni cuestionada, por ello mismo, es semi-consciente y pre-ontológica. La filosofía es una conciencia refleja, es un saber tanto suprasubjetivo como intersubjetivo: cooperativamente reflexionante. La conciencia directa, sin relación con la conciencia refleja en la que el pensamiento versa sobre sí mismo en relación con los objetos, es un realismo ingenuo, es decir, cree en una inmediata correspondencia entre el conocimiento y lo real, de igual modo que es conformista con la aceptación empírica de las costumbres admitidas. Por esta razón, la conciencia refleja introduce una revolución cultural en la historia de la humanidad en la que se piensa de acuerdo a la crítica conceptual y a la universalidad. En consecuencia, las ciencias y las disciplinas se desnaturalizan si no mantienen el diálogo entre el saber y el autosaber. Las ciencias y disciplinas sin la filosofía, no pueden examinar sus propios criterios de validez y se interceptan con la opinión habitual (doxa), sin embargo, teniendo en cuenta las teorías de la racionalidad de la comunicación en el habla, además de de la opinión habitual, en la vida social, se dan las razones cotidianas sustentadas en la argumentación débil. Las razones cotidianas también rodean el saber científico y disciplinario.

Para Hegel, la opinión habitual que sigue las convicciones tradicionales y la autoridad, puede transformarse en conciencia crítica a través del escepticismo: de la duda y del cuestionamiento. No obstante, una forma unilateral e incompleta de considerar el escepticismo, reduce todo el saber a una simple nada, al vacío, sin tomar en cuenta que la refutación es una parte básica del proceso del saber. El saber asume tanto positivamente como negativamente su pasado. Toda negación de un saber produce un resultado que conduce a una nueva forma del pensar que es autocorrectivo. Por esta fuerza de la negatividad, la meta del saber no puede comprenderse simplemente en lo adquirido sino también en* su proceso. ${ }^{14}$

La dificultad de este planteamiento sobre la dialéctica del saber es que este proceso es histórico y remite a la formación de la conciencia. Los diversos momentos de la verdad se conforman como estadios de la racionalidad. El criterio absoluto de la verdad, en consecuencia, no puede ser imperativo; es sólo regulativo: es la orientación hacia el indefinido examen de los presupuestos, lo cual es lo mismo que afirmar que el criterio absoluto es la libertad de la razón. Este absoluto no es ningún estado de cosas: es un proyecto que se realiza en su propio itinerario.

13. Cfr. HUSSERL, E. La filosofía en la crisis de la humanidad europea. En: La filosofía como ciencia estricta. Trad. Elsa Tabernig. Buenos Aires: Editorial Nova, 1969. p. 155.

${ }^{14}$. Cfr. HEGEL, G.W.F. Fenomenología del espíritu. Op. Cit. p. 55 
La libertad de la razón es, en primer lugar, la mayoría de edad intelectual, es decir, el juzgar desde sí mismo sin atenerse a la autoridad, dice Kant: "La minoría de edad es la incapacidad de servirse de su propio entendimiento." No obstante, la propia opinión, paradójicamente, como observa Hegel, en contra de la conciencia natural, también puede constituirse en dogma, con lo cual no se diferenciaría de la autoridad de los otros sino por su propia vanidad. 16 La libertad de la razón ha de atenerse, en consecuencia, al diálogo histórico entre el saber y el autosaber, y a la investigación dialógica que promueve la conformación de las nuevas estructuras de racionalidad.

Así en el siglo XX, se pasa de un diálogo vertical a un diálogo horizontal entre la filosofía, las ciencias y las disciplinas. Además, con las nuevas teorías y filosofías de la comunicación (o del habla) y de la argumentación informal, se pierde la ilusión que considera a la razón como un macrosujeto en devenir y aparece más bien un diálogo argumentativo intersubjetivo como lo ha propuesto Habermas, aunque, al parecer, sigue siendo indispensable considerar que el saber que asume su pasado.

El impacto de las nuevas consideraciones sobre la comunicación, se puede constatar en la epistemología de Khun, ${ }^{17}$ para quien las teorías ejemplares denominadas "paradigmas" son compartidas por la comunidad científica de acuerdo con procedimientos metodológicos y disciplinarios, además del prestigio de los grandes autores. Por el contrario, Koyré constata la fuerza de las grandes filosofías sobre la ciencia en el caso de la matemátización de la naturaleza en la física moderna que procede, en parte, de la rememoración de la filosofía platónica en el renacimiento, para la cual la matemática era un saber ejemplar, pero también, Koyré* investiga la historia de los conceptos en la ley de la inercia y en de la relatividad del movimiento, para defender el racionalismo y relativizar la filosofía empirista. ${ }^{18}$ Para Bachelar $^{19}$ incluso, el racionalismo dialéctico de la física contemporánea, permitió sobrepasar el racionalismo mecanicista mediante la elaboración de conceptos complejos con tensiones dinámicas. Por su parte, al estudiar la incidencia de la historia* de las ciencias sobre los criterios filosóficos, Lakatos, ${ }^{20}$ en la medida en que intenta constatar los criterios de la demarcación de la ciencia, es decir de su delimitación como campo del saber, concluye que el espacio de la cientificidad esta dado por su falibilidad, pues lo que se evalúa es la sucesión de teorías en

${ }^{15}$. KANT, I. Respuesta a la pregunta ¿qué es la ilustración? Trad. Ruben Jaramillo. En: Rev. Cuestiones de Filosofía. N 1, Tunja, UPTC, (Octubre 1993), p. 93.

16 . HEGEL,G.W.F. Fenomenología del espíritu. Op. Cit. p. 55

${ }^{17}$. KUHN, Th. La estructura de las revoluciones científicas. Trad. Agustin Contin, México: Fondo de Cultura Económica, 2a Ed., 1978.

18. KOYRÉ, A. Estudios de historia del pensamiento científico. Encarnación Pérez y Eduardo Bustos, México: Diglo XXI, 2a Ed. 1978.

19. BACHELARD, G. La actividad racionalista de la física contemporánea. Trad. Estela Canto, Buenos Aires: Siglo Veinte, 1a Ed., 1975.

BACHELARD, G. La filosofía del no. Trad. Noemí Fiorito, Buenos Aires: Amorrortu, 1a Ed., 1970.

20. LAKATOS, I. "La falsación y la metodología de los programas de investigación científica". En: La crítica y el desarrollo del conocimiento. Trad. Francisco Hernán, Barcelona: Grijalbo, 1a Ed. 7975 . 
cuanto programas racionales de investigación en su proceso histórico. En el desarrollo de las ciencias sociales y humanas, y en las disciplinas jurídicas y estéticas, también se ejemplifica la gran influencia de las filosofías de Kant y Hegel.

La relación entre el saber y el autosaber, en términos de teoría del lenguaje, tiene una analogía con la relación entre el lenguaje objeto y el metalenguaje, en la que el segundo se refiere al primero (como en el caso: el "perro" tiene cinco letras). Con las filosofías de la comunicación y de la comunidad científica, se pierde la dimensión lingüística del metalenguaje similar a al diálogo vertical entre saber y autosaber; se desvanece, también, en un convencionalismo, la dimensión histórica del desarrollo de la razón y de toma de conciencia defendidas por la filosofía hegeliana: "También el individuo singular tiene que reconocer, en cuanto a su contenido, las fases de formación del espíritu universal, pero como figuras ya dominadas por el espíritu, como etapas de un camino ya trillado y allanado." ${ }^{21}$.

\section{LA DIALÓGICA DEL FUNDAMENTO.}

Otra de las formas de fundamentación se remite a los principios categoriales (de cantidad, cualidad, causalidad, posibilidad, etc.) La filosofía moderna, especialmente a partir de Kant, se ha auto-definido como la búsqueda de los fundamentes a priori del conocimiento. Esos fundamentos son la sustentación trascendental del conocimiento, es decir, son las condiciones que se encuentran en la base de nuestro conocimiento y determinan su posibilidad o su imposibilidad: definen las formas del objeto en general (lo ontológico). Lo trascendental, en consecuencia, es una lógica de principios categoriales que define previamente lo que puede ser conocido. Al especificar de antemano las condiciones de acceso al objeto, se ponen los "marcos" dentro de los cuales éste nos puede ser dado. En la filosofía kantiana este marco trascendental esta conformado por la experiencia dada en el espacio y el tiempo, y ésta es organizada por los principios del entendimiento (la matematización, la causalidad, la posibilidad, etc.) y orientada por las ideas regulativas como totalidades presupuestas por las ciencias (la legalidad, la libertad y el conocimiento ilimitado).

Los conocimientos científicos y las disciplinas requieren un fundamento, en el sentido de estar basados sobre una racionalidad y sobre unos métodos. ¿De dónde habrían de salir tales fundamentos? Si se establecen unos criterios desde fuera de las ciencias y disciplinas ¿cómo se podría garantizar que esos criterios son adecuados para el objeto que se conoce? La propuesta de unos criterios para las ciencias y disciplinas dados por una instancia situada por encima de

21. HEGEL, Fenomenología del espíritu. Op. Cit., p. 21.

Considerar una evolución de la razón, no necesariamente implica una teleología de la autotransparencia de la conciencia, al modo hegeliano. Basta con considerar un progreso como la corrección de los errores, y la conformación de nuevas formas de racionalidad más amplias y universales, al mismo tiempo que su apertura a la pluralidad. 
ellas, podría ser arbitraria. De otra parte, las ciencias tampoco pueden ser desarrolladas o planteadas sin que, de antemano, se estipulen unos fundamentos o unas bases para evaluar su validez. Ante la carencia de unas orientaciones metodológico-racionales, los conocimientos científicos tendrían que ser recogidos al azar o de manera caótica. Las ciencias requieren, de todos modos, unas directrices que se anticipen al conocimiento futuro y que puedan dirigir y organizar racionalmente las investigaciones.

A diferencia de Kant, quien exige unos fundamentos metodológicos y racionales, Hegel introduce la dialéctica del fundamento en el interior de las ciencias. La ley de la gravitación, por ejemplo, es el fundamento de los movimientos del sistema solar; las leyes del equilibrio electrónico son el fundamento de la explicación de la formación de moléculas en la química. Pero, a su vez, el fundamento sólo puede ser comprendido sobre la fase del saber del objeto.

Para Hegel, la dialéctica del fundamento, se realiza en las ciencias (en sentido amplio), pero como en último término los criterios se generan en el interior de la filosofía, ella es el fundamento del saber en general, de su racionalidad. El fundamento es aquello por cuyo medio el saber tiene que ser comprendido cómo valido o racionalmente posible (ontológica y metodológicamente). Hegel piensa la dialéctica del fundamento para las ciencias, pero no para la filosofía. ${ }^{22}$ La identidad de los opuestos entre el saber del objeto y el saber del saber, no le permite ser consecuente con su planteamiento del fundamento. Para Hegel, la filosofía debe ser el puro despliegue interior de los conceptos, lo que le impide aceptar algo desde el exterior del sistema. Si la filosofía es el fundamento del conocimiento del saber cotidiano, de las ciencias y disciplinas, lo primero que podríamos preguntar es: ¿cuál es el fundamento de la filosofía? Antes de intentar contestar esta pregunta, tenemos que investigar la relación entre el fundamento (la filosofía) y lo que funda: las ciencias y las disciplinas (normativas y valorativas).

El marxismo, con su crítica a Hegel, inició el proceso de cuestionamiento a la autoconciencia como fundamento unilateral: la conciencia y la autoconciencia también está condicionada desde la exterioridad, desde el orden sociohistórico. El desarrollo de la conciencia filosófica no se realiza, solamente en la forma del pensar que vuelve sobre sí mismo, que en términos de Hegel es la autoconciencia, antes bien, de acuerdo con Engels, en su texto L. Feuerbach fin de la filosofía clásica alemana:

Desde Descartes hasta Hegel, y desde Hobbes hasta Feuerbach, los filósofos no avanzaban impulsados solamente, como ellos creían, por la fuerza del pensamiento puro. Al contrario, lo que en realidad les impulsaba eran precisamente los progresos formidables y cada vez más rudos de las ciencias naturales y la industria. 23

22 Cfr. HEGEL, G. Ciencia de la lógica. Trad. Augusta y Rodolfo Mondolfo, Buenos Aires: Hachette-Solar, 2a Ed., 1968.pp. 402-412.

23 . ENGELS, F. Ludwig Feuerbach, fin de la filosofía clásica alemana. En: Obras escogidas. Moscú, Progreso, 1969. p. 641. 
El saber se conforma través del tiempo, en su relación productiva con el mundo natural y sociocultural. El saber no se efectúa en la interioridad de sí mismo; tiene una relación recíproca con su propio objeto. En la medida el que el sujeto interactúa y elabora intelectualmente el objeto, incide sobre éste, interpretándolo y transformándolo. Esta reciprocidad es doble: en su actuar con los objetos (naturales y socioculturales), el sujeto intersubjetivo se transforma a sí mismo.

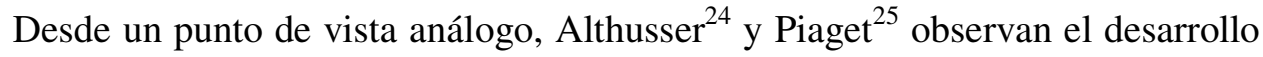
en cierto modo paralelo, entre la filosofía y las ciencias: Platón, en relación con las matemáticas; Aristóteles, con la lógica formal y la biología; Descartes con la física de Galileo y la geometría analítica; Kant con la física de Newton y la revolución francesa. Hegel con la química, la física de la fuerza y la energía, la geología, la biología y la historia; Marx, con la teoría de la historia y la economía política. A estas relaciones se podría agregar: el Círculo de Viena con la lógica matemática y la semántica; Husserl, Wittgenstein y Habermas con la linguística; Piaget con la psicogénesis; Heidegger y Cassirer con la antropología cultural y las teorías del lenguaje, y el Círculo de Frankfurt con las sociologías de Weber, de Marx y el psicoanálisis de Freud. En la época contemporánea, de modo especial, la "experiencia de la conciencia" o la formación de la racionalidad, debe tener en cuenta las ciencias reconstructivas que investigan la formación del entendimiento: en el aprendizaje estudiado por la sicología cognitiva, la epistemología histórica, la teoría de la argumentación y la acción comunicativa.

En la dirección de una dialéctica dialogante, la reflexión filosófica consiste en elevarse, por vía reflexionante, desde el saber del objeto hasta sus bases. El fundamento tiene que ser derivado del saber que él pretende fundar. De este modo, el fundamento se revela como reflejado, como puesto y deducido de lo fundado. El fundamento, como tal, es una base a partir de la cual se sustenta el saber, pero sólo tiene sentido en tanto referido a otro, que es la multiplicidad de lo fundado y del cual la reflexión deduce el fundamento. El fundamento es lo más universal y, como tal, es la esencia del saber.

El fundamento es revelado por la autorreflexión que investiga los criterios de validez y las condiciones del saber. Así lo fundado ha mostrado, a su vez, ser un fundamento. No obstante, siguen siendo diferentes en su contenido. Lo fundado (el saber) es una multiplicidad frente a la unidad que representan los fundamentos (filosofía). Frente a los criterios racionales (categoriales y metodológicos) planteados por la filosofía, las hipótesis particulares de las ciencias y tesis disciplinares parecen accidentales. Sin embargo, las bases metodológico-racionales son los fundamentos del conocimiento de las ciencias y disciplinas como unidades simples de sus condiciones o como formas ideales

${ }^{24}$. Cfr. ALTHUSSER, L. "Materialismo histórico y materialismo dialéctico". En: VERON, E. (Comp.). El proceso ideológico. Trad. Noelia Bastard y otros, Buenos Aires: Tiempo Contemporáneo, 2a Ed., 1971. pp. 173-195.

${ }^{25}$. Cfr. PIAGET, A. Naturaleza y métodos de la epistemología. Op. Cit. 
de la validez, éstos, a su vez, adquieren sentido y existencia por la multiplicidad de los saberes particulares. De esta exposición se deduce que el fundamento es relativo y representa una vinculación esencial con lo fundado. El fundamento traspasa al saber del objeto; así, la realización de este contenido es lo fundado, es un saber* mediato y dependiente. El contenido de lo fundado presupone la forma dada por el fundamento, y el fundamento, a su vez, presupone lo fundado.

El fundamento y lo fundado se refieren entre sí como a su otro que les da existencia y sentido. En su simplicidad, el fundamento se diferencia de la diversidad de las ciencias y disciplinas pero depende de la multiplicidad de lo fundado. El fundamento y lo fundamentado se retroactivan. De esta manera, en el fundamento retroactivo, las bases del saber son recíprocas con el saber efectivo de las ciencias y las disciplinas; esta retroacción es histórica y está surcada por la polémica intersubjetiva. En la dialéctica, dice Engels, la filosofía cambia de forma con los nuevos descubrimientos científicos. 26

Si bien es ineludible fundamentar las ciencias y las disciplinas de modo racional, esta fundamentación se debe pensar como una revolución postcriticista. La constitución racional de las ciencias y disciplinas, el establecimiento de sus bases a priori en cuanto principios racionales y métodos, además de la consideración de sus límites, es, para Kant, el concepto de crítica. En una dialéctica dialogante este a priori se funda como resultado del proceso histórico, pues la dialéctica remite a la reciprocidad entre el fundamento y lo fundamentado. Al tomar en cuenta la retroacción entre el $a$ priori y los resultados de los procesos de la elaboración del saber, o lo $a$ posteriori, la filosofía se somete al replanteamiento de sus propios fundamentos.

El proyecto de la filosofía se mueve en la dirección de plantear las condiciones de posibilidad de las ciencias y disciplinas o, en otros términos, intenta constituír la forma ideal de la validez del saber. Las ciencias y disciplinas elaboran la "esencia" articulada de los objetos de conocimiento (en diversos modelos: funcionales, estructurales, participativos, etc.); la filosofía, a su vez, reconstruye las condiciones ideales dentro de las cuales es posible el trabajo de los saberes. En la función de desentrañar el concepto de cientificidad y legitimidad de las disciplinas, la filosofía tiene que constituír un priori racional y metodológico, o un orden lógico que sirva de "marco" para todo conocimiento* científico y disciplinario. La posibilidad de toda teoría no es otra que la inteligibilidad de la teoría en general. La filosofía no plantea una teoría, sino el concepto mismo del saber científico y disciplinario posible. La determidación de la "esencia" de la cientificidad, de la legitimidad y de los valores, es la demarcación de unos límites racionales, dentro de los cuales el saber se efectúa.

La filosofía fundamenta un orden ideal de los saberes que es "justificado" a través de los procesos históricos de elaboración de conocimientos. Son las

26 Cfr. ENGELS, F. Ludwig Feuerbach, fin de la filosofía clásica alemana. Op.cit. p. 607. 
mismas ciencias y disciplinas las que permiten la fundamentación filosófica e, inversamente, es la filosofía la que explora la posibilidad o las bases sobre las cuales se constituye el saber. Si, para Kant, no es posible ningún constitutum, o ninguna pluralidad de los conocimientos, sin las bases sistemáticas del entendimiento y la razón que son su constituens -lo cual es adecuado-, para la dialéctica ésta fundamentación, a su vez, es el resultado del devenir del saber, como observa Hegel; no obstante, él no siempre es consecuente consigo mismo, pues considera la verdad como el desenvolvimiento puro de los conceptos.

Las filosofías no dialécticas se refugian en una metafísica fundamentalista que se remite a un fundamento último, a una evidencia primera, o a unos principios incuestionables. Tal metafísica fundamentalista huye hacia un apriorismo, bajo la ilusión de que sus fundamentos no son resultado de los procesos del saber.*

Las filosofías no dialécticas se enfrentan a una antinomia dada por dos posibilidades: el saber tiene un a priori último y absoluto (incondicionado) o bien, el fundamento requiere, a su vez, de otro fundamento en proceso de regresión al infinito. Ante la historia del saber, ninguna de estas dos posibilidades puede ser sostenida. Todos los supuesto principios últimos e inmutables son barridos, relativizado, pluralizados o recontextualizados por la crítica constante del proceso de saber. Principios tan firmes como el determinismo total de la ley natural; el de la conservación de la sustancia (materia) y la impenetrabilidad de los cuerpos, que se encuentran en la filosofía kantiana y que también eran presupuestos de la física clásica, ya no pueden ser sostenidos por las ciencias contemporáneas. De otra parte, una regresión infinita de fundamentos es imposible.

El razonamiento dialéctico no propone ni un a priori racional último y definitivo, ni la imposible regresión al infinito. La investigación filosófica de la dialéctica se realiza frente a la historia del saber y consciente de circunscribirse en la conciencia social epistémica de cada época. La dialógica del fundamento concluye en una circularidad abierta e inter-fundante, es un desarrollo en espiral que asume su pasado. Al respecto Piaget observa, no sólo que las ciencias incluyen epistemologías regionales, sino además, que el aprendizaje implica formas de retroalimentación y autorregulación. Incluso, en las ciencias y en la tecnología contemporánea este proceso cibernético de retroacción puede ser formalizado. ${ }^{27}$

A lo largo del siglo XX las ciencias y las disciplinas se han especializado, autonomizado y diversificado. Esto significa que se ha profundizado en saberes más circunscritos; se investiga a partir de los propios principios de inteligibilidad disciplinaria. El saber se* mueve en múltiples niveles de elaboración conceptual (desde lo altamente teóricos, hasta la simple información descriptiva o estadística). Múltiples filosofías se apoyan en la historia de la ciencia con resultados muy diversos, pues necesariamente toda filosofía tiene que seleccionar e interpretar sus ejemplos; esta situación parece introducir un inevitable relativismo. No obstante, recurrir a la "materia prima"

27. Crf. PIAGET, J. y otros. Epistemología genética y equilibración. Trad. José Manuel Revuelta. Madrid: Editorial Fundamentos, 1981. 
de la historia del saber es válido y objetivo en la medida en que se aborda la diversidad de las ciencias y disciplinas en sus diversos niveles de elaboración y multiplicidad. La unilateralidad a partir de una de sus especializaciones sólo nos puede dar una visión también parcial del saber. La filosofía de las ciencias debe retomar sus resultados más complejos para que, de este modo, se pueda exponer el desenvolvimiento lógico del saber, en vez de limitarlo a sus formas más elementales.

La investigación reflexionante del a priori filosófico, pasa por la apropiación a posteriori del saber $\mathrm{y}$, una vez constituidas las formas ideales de cientificidad, legitimitad y valoración, éstas se transforman en perspectivas de anticipación para la ciencia y las disciplinas futuras. Las orientaciones de la cientificidad se conservan, hasta que el saber, en su incesante proceso, demande a la filosofía repensar los criterios y la obligue a reelaborarse a sí misma y a su contexto. En la dialéctica dialogante la filosofía se funda a sí misma como coordinación de sistemas abiertos. "La única filosofía que comienza sin supuestos es aquella que tiene la libertad y el valor para cuestionarse a sí misma", dice Feuerbach. 28

28 FEUERBACH, L. Aportes para la crítica de Hegel. Trad. Alfredo Llanos, Buenos Aires: Pléyade, 1973. p. 38.

\section{BIBLIOGRAFIA}

ALTHUSSER, L. "Materialismo histórico y materialismo dialéctico". En: VERON, E. (Comp.). El proceso ideológico. Trad. Noelia Bastard y otros, Buenos Aires: Tiempo Contemporáneo, 2a Ed., 1971. BACHELARD, G. La actividad racionalista de la física contemporánea. Trad. Estela Canto, Buenos Aires: Siglo Veinte, 1a Ed., 1975.

BACHELARD, G. La filosofía del no. Trad. Noemí Fiorito, Buenos Aires: Amorrortu, 1a Ed., 1970. DIAZ, A. Jorge Aurelio. Estudios sobre Hegel. Bogotá: Universidad Nacional de Colombia, 1986.

ENGELS, F. Ludwig Feuerbach, fin de la filosofía clásica alemana. En: Obras escogidas. Moscú, Progreso, 1969.

GARAUDY, R. Dios ha muerto: Estudio sobre Hegel. Trad. Alfredo Llanos, Buenos Aires: Ediciones siglo XX, 1973

FEUERBACH, L. Aportes para la crítica de Hegel. Trad. Alfredo Llanos, Buenos Aires: Pléyade, 1973. HABERMAS, J. Teoría de la acción comunicativa: racionalidad de la acción y racionalización social. T. I. Trad. Manuel Jiménez Redondo. Madrid: Taurus, 1989.

HEGEL, G. Ciencia de la lógica. Trad. Augusta y Rodolfo Mondolfo, Buenos Aires: Hachette-Solar, 2a Ed., 1968.

HEGEL, G. Fenomenología del espíritu. Trad. Wenceslao Roces. México: Fondo de Cultura Económica, 1966.

HEIDEGGER, M. "El concepto hegeliano de experiencia". En: Sendas perdidas. Buenos Aires: Losada, 1960.

HEIDEGGER, M. La pregunta por la cosa. Trad. Eduardo García B. y Zoltan Szankay. Buenos Aires: Alfa Argentina, 1975.

HUSSERL, E. La filosofía en la crisis de la humanidad europea. En: La filosofía como ciencia estricta. Trad. Elsa Tabernig. Buenos Aires: Editorial Nova, 1969.

KANT, I. Respuesta a la pregunta ¿qué es la ilustración? Trad. Ruben Jaramillo. En: Rev. Cuestiones de Filosofía. N 1, Tunja, UPTC, (Octubre 1993),

KUHN, Th. La estructura de las revoluciones científicas. Trad. Agustin Contin, México: Fondo de Cultura Económica, 2a Ed., 1978 .

KOYRÉ, A. Estudios de historia del pensamiento científico. Encarnación Pérez y Eduardo Bustos, México: Diglo XXI, 2a Ed. 1978. 
FEUERBACH, L. Aportes para la crítica de Hegel. Trad. Alfredo Llanos, Buenos Aires: Pléyade, 1973.

PIAGET, J. y otros. Epistemología genética y equilibración. Trad. José Manuel Revuelta. Madrid: Editorial Fundamentos, 1981

LAKATOS, I. "La falsación y la metodología de los programas de investigación científica". En: La crítica y el desarrollo del conocimiento. Trad. Francisco Hernán, Barcelona: Grijalbo, 1a Ed. 7975

PIAGET, A. Naturaleza y métodos de la epistemología. Buenos Aires: Proteo, 1970.

PIAGET, J. Psicología y epistemología. Trad. Francisco J. Fernandez Buey. Barcelona: Ariel, 1975,

PIAGET, J. y otros. Epistemología genética y equilibración. Trad. José Manuel Revuelta. Madrid:

Editorial Fundamentos, 1981.

VATTIMO, G. Las aventuras de la diferencia: pensar después de Nietzsche y Heidegger. Trad. Juan Carlos Gentile. Barcelona: Ediciones Península, 1980. 